\title{
8
}

\section{Creative Storytelling and Self-Expression among People with Dementia}

\author{
ANNE DAVIS BASTING
}

\begin{abstract}
$W_{\text {hen memory fades and one's grasp on the factual building blocks of one's }}$ life loosens, what remains? Is a person still capable of growth and creative expression even when dementia strikes? To answer these questions, I relay the story of the TimeSlips Project, a research and public-arts storytelling project aimed at nurturing creative expression among people with Alzheimer's disease and related dementia (ADRD) and at sharing the stories that emerged in TimeSlips workshops with the public at large to increase awareness of the creative potential of people with ADRD. I will (I) outline the storytelling method and my study of it; (2) analyze the content of the stories; (3) discuss interviews with staff, family caregivers, and student participants; and (4) describe the TimeSlips's outreach program's effectiveness in changing public perception of people with ADRD.
\end{abstract}

\section{The Storytelling Method}

The Timeslips storytelling method evolved out of a year of experimenting with a variety of exercises in creative dramatics. After espousing the virtues of theatrical performance for older adults in my research on senior theater troupes across the United States, I wanted to see if "playing a new role" could benefit people with ADRD as much as I found it did for the well elderly. People with dementia clearly have few meaningful social roles available to them. With holes where memories of their children and spouses used to be, people with ADRD often lose even the most basic roles available to us all-that of partner or parent. In creating the TimeSlips method, I set about to establish a social role for people with ADRD, that of storyteller, that would in turn provide access to meaningful self- 
expression. After running a storytelling circle for three months in a long-termcare facility, I set up a research study of the storytelling method to test its effectiveness in four adult day centers, two in Milwaukee, Wisconsin, and two in New York City. The storytelling method has evolved in the years since the research study began in I998. What I describe here is the structure of the storytelling circles in those four initial adult day center test sites.

The TimeSlips storytelling method followed a clear, ritualized structure. At least once a week, a group of people with symptoms consistent with middlestage Alzheimer's disease gathered in a circle of chairs. ${ }^{1}$ With the program assistant, Nichole Griffiths, I trained undergraduate students from a wide range of disciplines (predominantly in the humanities and arts) to facilitate the storytelling. Students and staff worked together to encourage the storytellers to respond to a picture the students brought in each week. Throughout this chapter, I refer to students and staff as facilitators and the people with ADRD as storytellers. The storytelling circles began with a "welcome," in which the facilitators introduced the activity and greeted the storytellers. Facilitators then read back a story from the previous week to prove to the storytellers that they were indeed capable of creative expression. Next, facilitators handed out an image to each member of the storytelling circle and asked open-ended questions (avoiding "yes" or "no" questions) of the group. One facilitator wrote down all the responses on a sketchpad large enough for all the storytellers to see. All responses, including any nonsensical answers, were validated and woven into the fabric of the story. Facilitators reread the story when they noticed the storytellers' attention starting to drift. A single story often lasted up to one hour, but most ran around thirty minutes on average. In the final step in the ritual, facilitators thanked all the storytellers in turn for their input as a way to acknowledge the significant risk and energy demanded by a full hour of creative storytelling.

Facilitators used a wide variety of images, but all shared one characteristic-they appeared staged or fantastical in some way. We avoided images of celebrities or family photographs because we found that storytellers became too fixated on the "real" story behind the image to freely launch into the realm of the imagination. The images guided facilitators in their choice of questions, which were carefully worded to give the storytellers ownership over the story. Instead of, "What is this character's name?" for example, a facilitator would ask, "What would you like to call him?" Questions focused on the sensory ("What sounds do you imagine in the background?") and on the world outside the picture as well ("Does he have a family?").

The free-form storytelling process demanded that facilitators leave behind preconceived notions of what constitutes a "story." If several storytellers responded with names for a single character, that character had several names. Events often took place in several places at once. Multiple plot turns created a 
meandering story line that read more as a chronicle of the storytelling process than as a traditional, linear story with a clear beginning, middle, and end and a focus on conflict and resolution. Because facilitators reassured the storytellers that they could say anything they wanted, since they were making up a new story, the facilitators often received answers that did not make sense to them. These were of two kinds. First, some were clearly meant to challenge the facilitators' promise that they would accept any answer. We referred to these as challenge answers. In one exchange, for example, a facilitator asked for a name for a character and promised she would accept any answer. A storyteller looked up at her slyly and said, "Oh, yeah? A-B-C-D-E-F-G." The facilitator wrote down the response and the name "A-B-C-D-E-F-G" became part of the story. The second type of nonsensical answer emerged from the domain of the disease. Several storytellers in each group had great difficulty with language. As the storytelling workshops proceeded and they grew to trust the process, these storytellers would often respond by adding fragmented words or sounds. Facilitators repeated these answers back to them and wrote them down as well as they could capture them.

This free-form style of storytelling runs counter to theories of narrative healing that are now gaining recognition in all corners of health professions. From the outside, the Timeslips method appears to be a "chaos narrative," in the words of Arthur Frank. Such nonlinear narratives are not thought to lead to healing, but stall the patient in the limbo of unresolved and undirected emotions. I argue that Frank's definition is text based-and not focused on process. The TimeSlips storytelling may look "chaotic" in terms of text, but the process has a linear narrative underneath it. People with dementia, silenced by confusion and the social pressure to say the right thing, learn to experiment with language and form social bonds with staff and participants in the process. As long as that narrative is clear to all participants (staff and people with Alzheimer's), I believe, the nonlinear form of the stories-or any other creative activity - can be part of a healing process. And in fact, we found that facilitators' attempts to make the narratives of the story linear shut down the process entirely.

\section{The Outreach Program}

The second goal of the TimeSlips Project was to share with the public the stories that emerged in the storytelling circles in order to increase awareness of the creative capacity of people with ADRD. We did this in several ways. First, the facilitators and TimeSlips staff created books of the stories told at each center and presented them to the storytellers in celebrations held at each facility. Second, in both Milwaukee and New York, a team of artists associated with the project produced a play (with professional actors) and an art exhibit inspired by 
the stories told in each city. Each performance of the play was followed by a postshow discussion in which audience members could share their reactions to the stories and ask questions about the disease. Third, we created a Web site that included stories from all four test sites as well as detailed information about the history and aims of the project.

\section{The Research Model}

We received approval from the Institutional Research Board (IRB) at the University of Wisconsin-Milwaukee and secured consent forms from all participating staff, students, and family caregivers as well as assent forms from all participants with ADRD. My assistant and I interviewed staff, students, and primary family caregivers at the outset of the project, in the middle of the storytelling sessions, and again at the end of the project. We held the interviews in person or over the phone, depending on the interviewee's preference. The interviews were "open structured," loosely following our aim to assess interviewees' reactions to and observations of the storytelling sessions without leaning on a prefabricated set of questions. The responses that I share here retain the anonymity of the subjects. Gender or other details of the respondent may be changed to protect their identity. In this chapter, I refer to the adult day center test sites as A and B (both in Milwaukee), and C and D (in New York).

To test the outreach model, we received approval from the Hunter College IRB, in New York. The main aim of this study was to test whether the art exhibit, play production, or both, generated a change in audience members' perception of the creative potential of people with ADRD. To address this, TimeSlips staff created an evaluation form and inserted it in each play program. A separate evaluation was also available at the art exhibit. All responses were anonymous. Although we held a play and art exhibit in Milwaukee, all responses were anecdotal. This research, therefore, focuses on the New York play and art exhibit.

\section{Analysis of the Stories}

All told, the storytelling workshops in all four sites yielded more than one hundred stories. Some stories were only partially complete, as facilitators tried to squeeze in one more tale before the hour was over. Of the completed stories, I analyzed seventeen from Center A and twenty-one from Center B. From the New York workshops, I analyzed sixteen from Center C and Io from Center D. I discerned the stories' main themes and noted their unique qualities, such as the prevalence of humor or nonsensical answers. Although the stories reflected the unique personality and diversity of each storytelling group, several themes emerged in all four groups. I will focus on individual groups first, and then turn to themes that appeared in all four. I will mainly refer to portions of stories. Full 
stories and additional information are available on the project's Web site (http:// www.timeslips.org).

\section{Center A}

Storytelling workshops in Center A featured a fairly consistent group of up to twelve enthusiastic participants who regularly added songs and even dances to their stories. Of the seventeen stories I analyzed, humor appeared in all; and eight featured main characters that were happy, confident, and likable. These characters commonly encountered social obstacles, including the negative opinions of people around them. The characters most typically overcame these obstacles by remaining true to themselves.

The most common theme that appeared was the desire for freedom-to make decisions, to be uninhibited, and to make choices. In "All the Way to Seattle," a woman pilot flies "because it makes her feel free, and because her family doesn’t pay her enough attention." In another story, "Italians from Ireland Getting Their Independence," the main characters are fighting for their “[Mil]Waukean independence and they are doing what's right.” The story's final line, "They got it right where they want it," asserts the characters' power and freedom. In the story "Look at Those Legs," a woman rides to church on an ostrich only to be ridiculed by her fellow congregants. She overcomes this ridicule "because she is very sophisticated" and leads the church in the song "Amazing Grace.”

References to religion and spirituality were also common in this group. In "I'm Glad You're Dead, You Dog, You," the two main characters are wrestling over a picture of the Virgin Mary "because she symbolizes all that they desire." In "She's down There under the Puppy," an elephant named Grandfather is not allowed to enter a church because he might break down the walls. He takes solace in his friendship with a little girl who is not afraid of his size, and together they sit outside the church and listen to the choir sing "Abide with Me."

Another common theme that emerged in the stories of group A was the desire for human relationships, both platonic and intimate. Two main characters in one story, two nuns, were in love, but couldn't remember with whom. Sexual innuendo was common. In "Tiny Bubbles," the main character lives underwater and is thinking about a woman he left on the shore. "He's thinking a whole lot about that woman," said a storyteller. In "It Goes Toot Toot," John Hibby and Bill Hobby and their wives "all fool around together." Explicit sexual references were not uncommon and could make some storytellers uncomfortable. Rather than edit the story, however, which would run counter to our promise to the storytellers that we would include all their responses, we simply encouraged more responses.

Several stories from group A dealt with difficult relationships. Some re- 
flected disagreements between children and their parents. In one story, for example, the children sharply disapprove of their parent's wrestling. Some stories joked about traditional gender relationships; men would commonly take on women's duties, as in "Italians from Ireland," where eight women were fighting for independence while their husbands were washing dishes.

The group at Center A was warm and supportive, comfortable with responding to the facilitators' questions with nonsensical answers. For example, in "Everybody Is Eating Corn," a story of a raucous dinner party at a restaurant, one of the main characters is "allegering all over the horn." Nearly every story at Center A featured a fragmented or nonsensical answer. But taken in the context of the storytelling circle, such answers had clear emotional resonance. When repeating nonsensical answers in the retelling process of the storytelling, facilitators aimed to capture the emotion intent behind the sound or words. "Allegering all over the horn" was, in context, a clear reference to a joyful celebration at the dinner party.

\section{Center B}

At Center B in Milwaukee, we worked with a group of storytellers who were much more mixed in their abilities than those in the group at Center A. Of the six storytellers at Center B, one storyteller had practically no verbal language at all. Because communication was more difficult for this group of storytellers, the pace of storytelling was slower here. Several unique characteristics emerged in the stories created by this group, possibly because of the smaller size and slower pace, but certainly because of the strong personalities of several storytellers. Of the seventeen stories in Center A, none included the names of storytellers. In Center B, however, almost half of the twenty-one stories I analyzed included the name of a storyteller or student facilitator as characters. When asked to name a character, some of the group's less verbal storytellers would point to a fellow group member instead of naming the person directly. Drawing fellow storytellers into the tale was sometimes used as a gesture of intimacy and, at other times, a gesture of friendly mocking. Either way, it always drew the group into a deeper engagement with the process. Facilitators called out and emphasized the storyteller's/character's name repeatedly with each retelling, acknowledging the storyteller's presence, creativity, and new role (as character).

Nearly all the stories at Center B contained "challenge" answers and answers that sharply redirected what might be the assumed journey of the tale. Their stories were less concerned with the direction of the plot and much more focused on wordplay. "He's a Tuba Player," for example, begins with "He's Tony the trumpet player from Tampa, trying to get a tune." Tony's wife, whose name is "Music," is "rumored to be dead." In "Thanksgiving Celebration," their story based on an image of a boisterous dinner party, storytellers named one couple 
"Pardon Me, I Burped" and "Charles, Who Is No Prince." "When the check comes” for the dinner party, "they'll sober up!” said one storyteller.

Although the members of this group commonly used their own names as the names of characters, they also tended to separate themselves from the story lines and in turn from fellow storytellers. For example, in a story about a pancakecooking club, one storyteller said, "I wouldn't join that club." In "Waltzing Ladders," when one storyteller said, "Everyone is married and has children so they don't have parties anymore," another countered with, "Then I'm never going to get married!" When one storyteller added church music to a story, another countered with, "No, that's too holy."

In spite of their penchant for sharp wit, participants in Center B also created some remarkably poignant images in their stories that seem to mirror their own feelings and fantasies. Tony the trumpet player, for example "should be fortytwo, but he's ninety-nine. He's happy, even though he's alone." In "We Want to See Castro," a little girl goes to Cuba with an elephant. "She's gone far away," said one storyteller, "because kids do that." In response to an image of a man hiding his head in his coat, storytellers named the main character "Headless Joe Wonder" and said that "he lives in a room of despair. He takes it as it comes. You think you can’t do anything without a head, but headless Joe Wonder can.”

\section{Centers C and D}

The storytelling groups at both New York Centers C and D fluctuated dramatically in size from week to week. Center $C$ had an average of ten storytellers; they ranged considerably in verbal skills, with the majority able to put together two or three words. At Center $\mathrm{C}$, the names of storytellers found their way into the tales, as they had at Center B. But at Center C, storytellers sometimes competed with one another to add their own name to the stories. In one story about a male painter and his female model, for example, two women storytellers added their own names to the name of the female model. We included both and hyphenated the character's name. Similarly, in "Mama Bear Does the Cha-Cha," Mama Bear is named after one of the storytellers. The story grew poignant as the storytellers decided that Papa Bear was far away having affairs, but that Mama Bear didn't just sit at home and mope. "Mama Bear and the two cubs are at home, doing the cha-cha." The namesake storyteller, confined to a wheelchair, would lead the group in a dance with her arms with each retelling.

There were few "challenge" answers at Center $\mathrm{C}$, and these stories generally featured likable characters and were peppered with humor. The raucous dinner-party image was imagined to be "John Gotti's birthday party," at which the characters were "eating diet food, because they are all fat!" In a story based on an image of an older couple arm wrestling, storytellers said, "They are falling in love for the first time." Like those of group A, members of this group were 
patient with non sequiturs that emerged out of illness, and they acknowledged the contribution of the storyteller who added them with each retelling. For example, one storyteller could not or would not answer with more than "I don't know." Facilitators asked if they could add this to the story, and the characters, a group of women accordion players, became the I Don't Know band. In another example, when asked if there was music in a story about a man with a pigeon sitting on his head, one storyteller enthusiastically made up a song whose only word was beep. To great approval from the crowd, she energetically sang it with each retelling of the story.

Center D's group was very small, although it never dipped below four participants. The group was more physically and emotionally fragile than the others and more linguistically challenged. One member could only add sounds, interspersed with occasional shards of words. Another storyteller had a remarkable gift for poetic images, but struggled to stay awake and to tolerate multiple stimuli. Her struggle was evident in her input to the stories; she often tried to either focus or silence the group. "Every person has a story," she said, "there's not a human being that doesn't have a story. But making it mish-mosh is bad. It's like a bomb." In other stories, however, her input encouraged the group to create powerful images. In a story based on an image of a man sitting in an enormous pile of books, they said "He is accepting responsibility to organize this into something. He is orchestrating an orchestra in his mind." In a tale about a can-can dancer who works with an ostrich, they named her "Holding On, because she's really just holding on.” The story ended with Holding On contemplating her career. "She never had children, and she thinks she might have missed something. But she has a complex sense of happiness."

As in other small storytelling groups, non sequiturs were much more common at Center D than in larger groups, in which the increased amount of input meant storytellers could edit themselves. In a story based on the image of the older couple wrestling, one storyteller looked perplexed and said, "All I know is Winnie the Pooh." Woven into the story, her response became a favorite phrase among the storytellers. As in other groups, the storytellers used the process to play with one another and with the staff. Their humor was vivid. In "An Exquisite Woman," a woman pilot flies to Russia, where she eats "chicken Kiev in a box." In "A Horse Is a Horse of Course," a handsome cowboy is "any age we want him to be ... probably twenty-eight. And he's attracted to beautiful women like us!"

\section{Comparing and Contrasting Centers}

Clear differences and similarities emerged in the four storytelling groups. Led by the strong personalities of group members and by the size and nature of the group dynamics, groups at Centers A and C yielded harmonious and playful stories, while Center B participants challenged the process at every step, and 
Center D's stories were powerful, dreamlike images pierced by sharp wit. As I mentioned earlier, common themes emerged in all four groups, including the desire for freedom, confidence, and intimate relationships. These desires were also evident in the group dynamics, where storytellers teased one another (and facilitators) by placing one another in the stories, by suddenly changing the direction of the story, or by adding deliberately humorous or provocative remarks. In all four groups, storytellers engaged in the process as a way to express themselves, whether they were attempting to contradict the flow of the story or encourage its progress-whether they were challenging facilitators or sharing a poetic image. In all four groups, storytelling provided storytellers with a valued social role and rare access to meaning-making for people whose language has broken down. Laughter and singing were a prominent part of all four storytelling groups as well, so much so that staff who were not directly involved with the storytelling tended to gather at the edge of the room to listen to the sessions. Clearly, the storytellers retained the capacity to entertain others and themselves with laughter, humor, and joy.

\section{Interviews: Volunteers, Staff, Families}

The storytelling process and the stories that evolve from it show that people with ADRD do have creative potential and can play a valuable social role. The stories themselves can tell us only so much about the effectiveness of the workshops; however, interviews with staff, family caregivers, and students can help us discern whether providing people with ADRD with access to a meaningful social role can shift the attitudes of people who care for them.

In Milwaukee, three students participated in the full eighteen weeks of workshops, and five of them facilitated storytelling for nine weeks. In New York, five students facilitated the nine weeks of sessions. All student facilitators were interviewed in their first week in the program and again at the end. During the project, they kept weekly journals of their feelings about the workshops. Interviews with students were open structured and focused on their perceptions of aging, dementia, and people with dementia.

Students in Milwaukee and New York City revealed an initial fear or substantial hesitation about working with people with dementia. Several articulated it as worry that they might hurt the storytellers, physically or psychologically. One student who was studying art therapy had considerable knowledge about dementia from gerontology courses but worried about her lack of practical experience working with such a population. Only one student had worked with people with dementia before and was fairly confident in her abilities. She, however, was fearful of revealing her own disability (dyslexia) in the group. The student volunteers had a high incidence of disability themselves. Of the thirteen students, three had dyslexia and another student was 
deaf. I can only speculate that they were especially drawn to a project that encouraged the growth of people with cognitive disabilities. But I can freely conclude that throughout the storytelling process, all four remarked that they gained confidence in their own writing and creative abilities.

After revealing their initial fear of working with people with dementia, the students were surprised at how much they enjoyed the sessions, as shown in their journals and in final interviews. They described the laughter and emotional connection that they had enjoyed with the storytellers as "giving meaning to their day" and making them feel as though they were "useful" and were "important" in the storytellers' eyes. After several weeks of storytelling, students commonly remarked that the storytellers did not seem to be afflicted with what they imagined to be symptoms of Alzheimer's disease. In their final interviews, three students shared their concerns that some of the storytellers were misdiagnosed.

Three students wrote about how it made them feel hurt when the storytellers did not remember their names from week to week. If certain storytellers did seem to remember the students, they felt particularly accepted. But two of these students also wrote that despite their not being remembered, they felt a good deal of satisfaction knowing that the storytellers trusted and accepted them. Two students described their growing understanding that the product, the story itself, was not the focus of the project. One student noted: "I think that at the beginning I was looking for the product. I was looking for the good story to come out at the end. And it was so hard! We just had to pull and push and it was like nothing was happening. And then it kind of hit me that we were not really there to get this good story. We were there to be with these people and, you know, maybe appreciate them for being individuals. You know it's to our advantage that we are there sharing with them their ideas and wisdom and creativity."

The students became very attached to both the process and the storytellers. By the end of the storytelling workshops, they were all able to separate their fears of the disease from their dissipating fears of the people who suffered from it. After the initial, cautious few weeks, the body language, vocal tone, and energy level of the students grew as they interacted easily with the storytellers.

Interviews that I conducted with staff at the four day centers revealed their surprise at the storytellers' creative abilities. Open-structure interviews at the beginning and end of the process showed that staff experienced a growing appreciation of the process and observed positive behavioral changes in clients. The Center B staff were not directly involved in the storytelling process but remarked in interviews that they regularly read the stories and noticed improvements in the center's clients: "We have a few people who are in the project who are very, very quiet, and I'm very happy to see them coming forward. The first couple of sessions ... they were very quiet and you really had to pull everything 
out of them and now I've noticed that as each class has been happening, they are more and more open; they'll talk openly and they're more comfortable. They are so happy after you leave, and honestly, we can really get a lot out of them for the rest of the day."

Staff at Center $\mathrm{C}$ were also not involved at the outset of the storytelling workshops. At first they were grateful for our giving them an hour in which to invest their attention elsewhere. After the third storytelling session, however, staff were increasingly lured by the laughter and singing in our circle. In the final few sessions, staff had joined the circle, asking questions and laughing and singing with us. Interviews with the two key staff members at Center $\mathrm{C}$ suggest two things: staff were surprised by the quality of the stories; and staff gained insights into clients that they had not previously imagined were possible to obtain. One staff member put it this way: "What they say, I mean, some of these stories... I gave them to [the director of the day center] and she said, 'Gee, these guys are smart! And funny!' And the family members, Ida's daughter, she read it. And she said, 'That story is funny!' She loved it. And I said, 'See? That's what we're doing here on Thursdays!"”

Staff at Centers A and D were fully involved in the storytelling from the beginning. They joined us in the storytelling circles on the first day and continue the storytelling to this day-a considerable commitment considering that the average turnover rate of staff in this field is near Ioo percent. Center A went beyond what we had hoped. The TimeSlips Project presented each center with books of all the stories, inexpensively duplicated and spiral bound. The staff at Center A took the initiative to put together (and pay for) three-ring binders and plastic page protectors for high-quality duplications of each image and its corresponding story. They invited the families of storytellers to attend a party at which the staff presented the beautiful books to all the storytellers, each receiving a copy, and thanked them for their contributions. The event was quite moving, as storytellers reviewed their efforts with their families. One storyteller took my arm and said, "You know what's so great about this? It ain't cheap!” I knew just what he meant. The books that the staff had created were works of art, honoring and giving value to the storytellers' creativity. The director of Center A, who was actively involved with the storytelling sessions, offered these remarks: "Being an active participant in this TimeSlips Project, I have seen the joy that the process has brought to the participants, the comfort that it has brought to families, the satisfaction and empowerment that it has brought to staff involved. I am also impressed by the insight and awareness that it has brought to the students, as they grow in their understanding of aging, disease, and [the] development of humanness."

THERE WERE RADICAL differences between the interviews with family caregivers that occurred in Milwaukee and those that took place in New York. All but two 
storytellers in Milwaukee lived with family members. The two lived in longterm-care programs and attended day centers for added social interaction. In New York, the few storytellers who lived with their families commonly also had at least part-time, paid attendants to care for them. Perhaps because of differences in the structure of care, or because of the gaps in communication with the day centers, only two of the family caregivers we interviewed in New York were aware of the stories. Consequently, they had little information to offer about changes in observed behavior.

Milwaukee families had a much greater awareness of the storytelling process and its impact on the storytellers themselves. Of the fifteen family caregivers we interviewed in Milwaukee, the majority had read the stories either in the single sheets we sent home each week or in the books of stories that we presented to storytellers at the end of the project. ${ }^{2}$ Three family caregivers said that they regularly read the book with their loved one with ADRD. Two said they duplicated the books and sent them to other members of the family as a way for them to understand and connect with the storyteller. One told us that the storyteller had become possessive of the book and hid it from her, calling it "his work." Four family caregivers told us that they believed that the storytelling made a clear difference in their loved one's behavior. These changes included initiating more conversation, exhibiting less confusion, and expressing an increased sense of enjoyment in life. Within couples, caregivers face tremendous challenges caring for someone with ADRD, not the least of which is the adjustment to the change in roles the couples play. I find the fact that family caregivers could find meaning and affirmation in the stories and the storytelling process in the face of these challenges a testament to the power of creative self-expression.

\section{Educational Outreach: Changing Public Perception}

In Milwaukee and New York, the TimeSlips Project sponsored art exhibits and staged professional play productions inspired by the stories and characters that had been created in the storytelling workshops. Our aim was to improve audience members' perceptions about the creative potential of people with ADRD. In Milwaukee, we collected anecdotal responses to the exhibit and play, but in New York we created a more official analysis of the educational outreach model. Analysis of the New York data suggests that it is indeed possible to positively affect public perception of people with dementia.

The New York TimeSlips play was produced in an intimate (ninety-nineseat) downtown (off-off-Broadway) theater known for innovative performances. We selected theater as a genre because the physical presence of the actor on stage can create a sense of empathy with another human being in a way that film cannot, and because people with dementia exist in a fragile world that, like 
live performance, disappears after the moment has passed. Our hope was to capitalize on the intimacy of the space, the power of the present moment, and the potential to engender a sense of empathy for people with dementia.

The play is set in an adult day center, where a small group of people gather in a creative-storytelling circle. Weaving communal stories, they free themselves from their private struggles with Alzheimer's to create a wondrous world inhabited by fantastical characters that take on a life of their own. A can-can dancer conceals the long legs of an ostrich beneath her skirts; a singing cowboy serenades his devoted horse; a determined swimmer battles the Hudson to break a world record; and a bookworm struggles to liberate himself from a mountain of books. Through the storytelling process, these fragmented personalities band together to help one another complete their journeys even as memory fails their authors.

In New York, we inserted an evaluation form in each printed program and allowed time after the show and before a postshow discussion for audience members to complete the forms. We received 539 responses over the course of twenty performances throughout the three weeks of the production. We asked a series of general questions to ascertain audience members' ages, occupations, and experience with dementia. We also asked a series of questions directly about the play, including a request for a description of its theme. ${ }^{3}$ The most common response (34 percent) was "self-expression," or "expression of an inner life." Next, we asked people if before viewing the play they had thought that people with dementia could express themselves creatively, with a measure of I being "not at all," and Io being "quite well." The average response was 6.3, or in the area we described on the form as "somewhat." In the following question, we asked if after viewing the play they thought that people with dementia could express themselves creatively. The average response was 8.2.

We analyzed the before-and-after responses according to differences in age, experience, occupation, and date of the performance. Age did have an impact on people's responses, but it was a relatively weak one. We found that younger audience members were slightly more optimistic in recognizing the creative potential of people with dementia. Each age group went up approximately two points from before to after, but younger audience members began from a slightly higher place than that of older members.

Those with experience with dementia (personal or professional) were more positive in their views of the potential of people with dementia to express themselves creatively. Those without experience changed their attitudes more than did those with experience. Both groups increased from their before attitude to their after. Those who worked in health care began with a more positive attitude in comparison with those who did not. Both groups increased two points from before to after, but those in health care began and ended higher than those who 
were not. The differences, however, were weak, and the play had a significant impact on every group.

The art exhibit in New York City featured six two-dimensional silhouettes of characters from the stories that had emerged in the New York storytelling workshops. The figures ranged from eight to twelve feet in height and included a pair of waltzing ladders, a woman riding an ostrich, a swimmer, and an elephant. The story itself was handwritten on the figure, so viewers could read it in its entirety. The exhibit was held at the Elsa Mott Ives Gallery at Fifty-third Street and Lexington Avenue, where the figures appeared in the enormous second-floor windows, which overlook a busy intersection. Evaluation cards were displayed prominently in the exhibit, but in spite of high attendance, only seventeen viewers completed cards and dropped them in the evaluation box. The results were similar to what we found in the play. Seven people had personal or professional experience with ADRD, eight did not, and two did not answer this question. All seventeen respondents showed a positive change in their perception of the creative ability of people with ADRD. But the small number makes it difficult to generalize the results or to compare them with the results of the play evaluation cards.

\section{Conclusion}

Creative storytelling supplies a social role, one with value, that allows for the integration of past and present, and that acknowledges the strengths and potential of the present lives of people with Alzheimer's disease and related dementia. It offers storytellers an avenue for self-expression that frees them from the demands of memory and rational language, which they can no longer master. Creative storytelling can reorient the expectations of professional caregivers so that they are able to recognize new and untapped strengths of their clients, including the capacity for humor, creative imagination, and social skills. It offers staff an enjoyable activity that can also help them develop their creative potential. It offers student volunteers an opportunity to separate their fear of Alzheimer's disease and aging from the people with whom they associate these features and can be a first step toward encouraging young people to consider working or volunteering with the elderly. Where broken communication skills fracture relationships with family caregivers and their extended families, creative storytelling can provide a way for individuals to forge new relationships through poetic and openly symbolic expression.

Perhaps because most people assume that people with Alzheimer's disease have no meaningful present, caregivers tend to encourage them to remember the past and underestimate their remaining strengths. While I believe that reminiscence work can be very effective and fulfilling for people wrestling with 
the early stages of ADRD, it can lead to frustration and even shame among people in the middle stages, people whose ability to have access to and control language and memory can be severely impaired. For us as caregivers, shifting our focus from memory to creativity can open up channels of communication with people with ADRD and offer both client and caregiver the potential for growth. Sharing the creative products of people with dementia in a respectful way can be very effective in raising public awareness about the creative capacity of people who suffer from the condition. This two-pronged approach, both changing the mindset and actions of caregivers and assuaging the public fear of people who suffer from ADRD, is a step toward the cultural change for which gerontologists so urgently call.

\section{NOTES}

This chapter is based on Ann Basting, "Exploring the Creative Potential of People with Dementia: Dare to Imagine," in Mental Wellness in Aging: Strengths-Based Approaches, ed. J. L. Ronch and J. A. Goldfield (Baltimore: Health Professions Press, 2003).

The research phase of the TimeSlips Project received support from the Helen Bader Foundation, Incorporated; the Fan Fox and Leslie Samuels Foundation; the Isaac H. Tuttle Fund; the Brookdale Foundation; the Extendicare Foundation; Blue Cross and Blue Shield; the University of Wisconsin-Milwaukee; and the Brookdale Center on Aging/Hunter College.

I. Because some clients at the adult day facilities were not diagnosed with Alzheimer's, staff selected clients whose symptoms were consistent with that diagnoses. All participants experienced memory loss and confusion to such an extent that they could no longer function on their own. Some had very little language left at all. We did not rely on the Mini Mental State Exam (MMSE), as we found that even those who could not take the exam could participate in the storytelling process.

2. Interviews with family caregivers were open-structure telephone interviews, held in the first three weeks of the project and again at the end of the storytelling sessions. We also produced a series of arts events inspired by the creative stories, and we interviewed families again after they had attended the arts events.

3. The average age of audience members was forty-two. Fifty-eight percent had experience with dementia, either personal or professional, and 37 percent of audience members came from an arts background, while 2I percent came from health-care fields. 